\title{
Post-infectious myositis ossificans in medial, lateral pterygoid muscles: A case report and review of the literature
}

\author{
QIAN JIANG, MIN-JIE CHEN, CHI YANG, YA-TING QIU, \\ ZHEN TIAN, ZHI-YUAN ZHANG and WEI-LIU QIU
}

\begin{abstract}
Department of Oral and Maxillofacial Surgery, Ninth People's Hospital, Shanghai Jiao Tong University School of Medicine, Shanghai Key Laboratory of Stomatology, Shanghai 200011, P.R. China
\end{abstract}

Received January 15, 2014; Accepted September 3, 2014

DOI: $10.3892 / 01.2014 .2710$

\begin{abstract}
Myositis ossificans (MO) is a disease where heterotropic bone forms within a muscle or other type of soft tissue. MO is classified into two groups, MO progressiva and post-traumatic MO. It rarely occurs in the masticatory muscles and thus, only 20 cases involving the masticatory muscles have been reported since 2001. The majority of the reported cases occurred due to trauma, repeated injury or surgical manipulation. However, in a small number of cases, no specific traumatic event was identified as the cause of MO. To the best of our knowledge, this is the first case of post-infectious MO to be reported in the medial and lateral pterygoid muscles.
\end{abstract}

\section{Introduction}

Myositis ossificans (MO) is a disease where the formation of heterotropic bone occurs within a muscle or other type of soft tissue (1). MO is classified into two groups, MO progressiva (MOP) and post-traumatic MO (PTMO) (2). MOP is an autosomal dominant disease observed within families in which multiple heterotopic ossifications develop systemically in various muscles, fascia, tendons and ligaments of the body $(2,3)$. PTMO is characterized by heterotopic bone formation within muscle tissue as a result of a single or repetitive injury $(2,4)$. PTMO is frequently reported in the orthopedic literature and is prevalent in the quadriceps femoris and brachialis anticus, where there is high risk for injury. However, $\mathrm{MO}$ is rare in the masticatory muscles. Only 20 cases of MO in the masticatory muscles were identified during a review of

Correspondence to: Professor Chi Yang or Professor Min-Jie Chen, Department of Oral and Maxillofacial Surgery, Ninth People's Hospital, Shanghai Jiao Tong University School of Medicine, Shanghai Key Laboratory of Stomatology, 639 Zhi-zao-ju Road, Shanghai 200011, P.R. China

E-mail: yangchi63@yeah.net

E-mail: chenminjie00@126.com

Key words: myositis ossificans, infection, pterygoid muscle, computed tomography the literature (since 2001), which was conducted in the present study; 16 cases were associated with an evident traumatic cause and were diagnosed definitively as PTMO.

In the present study, a rare case of MO in the medial and lateral pterygoid muscles that was caused by odontogenic infection is presented, which was diagnosed as post-infectious MO (PIMO). To the best of our knowledge, this is the first case of PIMO in multiple masticatory muscles to be reported in the English literature. Written informed consent was obtained from the patient.

\section{Case report}

In January 2010, a 42-year-old female was referred to the Department of Oral and Maxillofacial Surgery, Ninth People's Hospital (Shanghai, China) with a complaint of the progressive, painless limitation of mouth opening for three years. The patient had no history of evident trauma, however, had experienced pain in the right upper jaw for approximately three years, for which the patient had not received any endodontic or periodontal treatment. In addition, the patient had experienced weakness when biting and chewing, which had endured for more than two years. The patient was administered with non-steroidal anti-inflammatory agents by The First Hospital of Jiaxing (Jiaxing, China), however, no clinical improvement was observed.

Physical examination revealed that the patient was well-nourished and demonstrated no evidence of developmental abnormalities. No facial asymmetry was apparent and the maximal incisal opening at presentation was $2 \mathrm{~mm}$. Despite the limited range of motion, the patient reported no associated pain or changes in the occlusion. On palpation the masseter and temporalis muscles were normal. The lymph nodes (submandibular and deep cervical) were nonpalpable and nontender. Intraorally, the right maxillary third molar residual root and missing mandibular central incisors were examined. The patient's dental hygiene was poor, however, the oral mucosa and tongue appeared to be healthy.

The patient's general medical status was normal and the laboratory tests, including serum calcium $(2.23 \mathrm{mmol} / \mathrm{l}$; normal range, $2.08-2.65 \mathrm{mmol} / \mathrm{l}$ ) and phosphorus levels (1.46 mmol/1; normal range, 0.78-1.65 mmol/l), were within the normal limits. A panoramic radiograph (Fig. 1) showed 
A
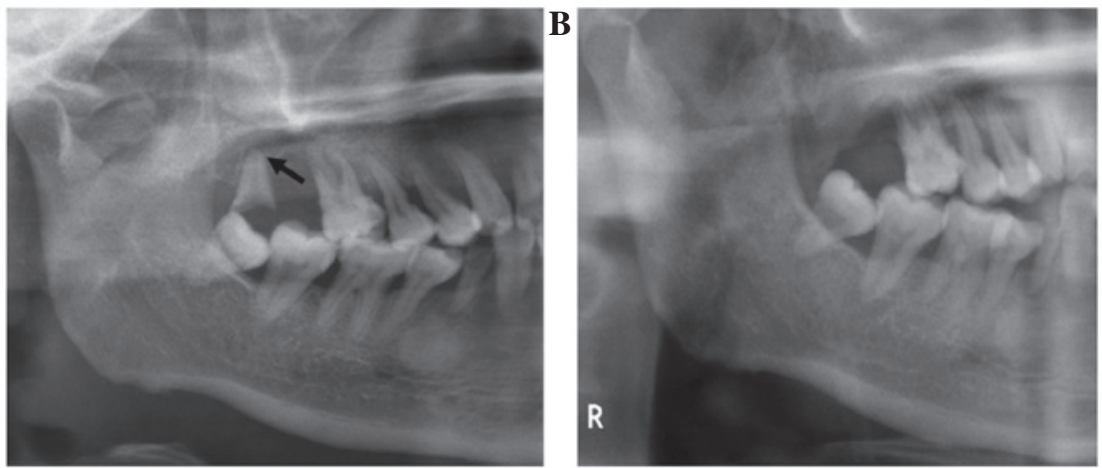

Figure 1. (A) Preoperative panoramic radiography shows the periapical lesions of the right maxillary third molar residual root (shown by the black arrow). (B) Postoperative panoramic radiography demonstrates the extraction of the residual root.
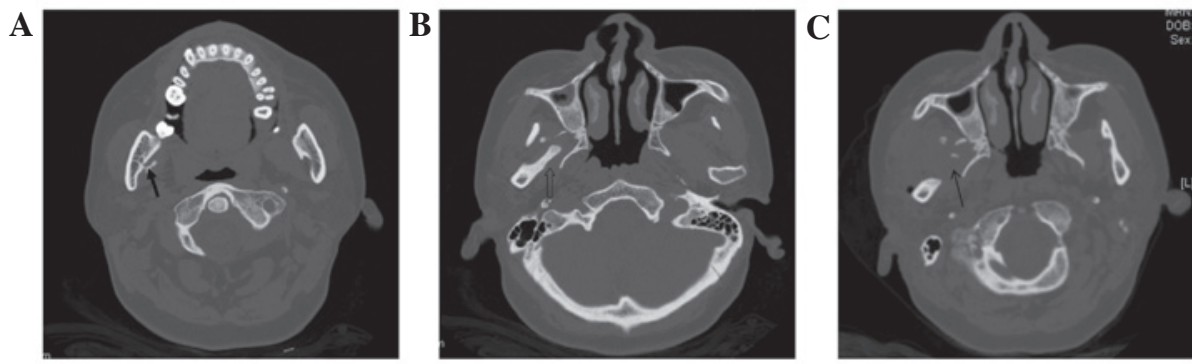

Figure 2. (A) Preoperative computed tomography (CT) scan demonstrating calcification in the right medial pterygoid muscle (solid arrow). (B) Preoperative axial CT showing calcification in the right lateral pterygoid muscle (arrow outline); (C) Postoperative CT scan demonstrating that the ossification was excised (arrow).
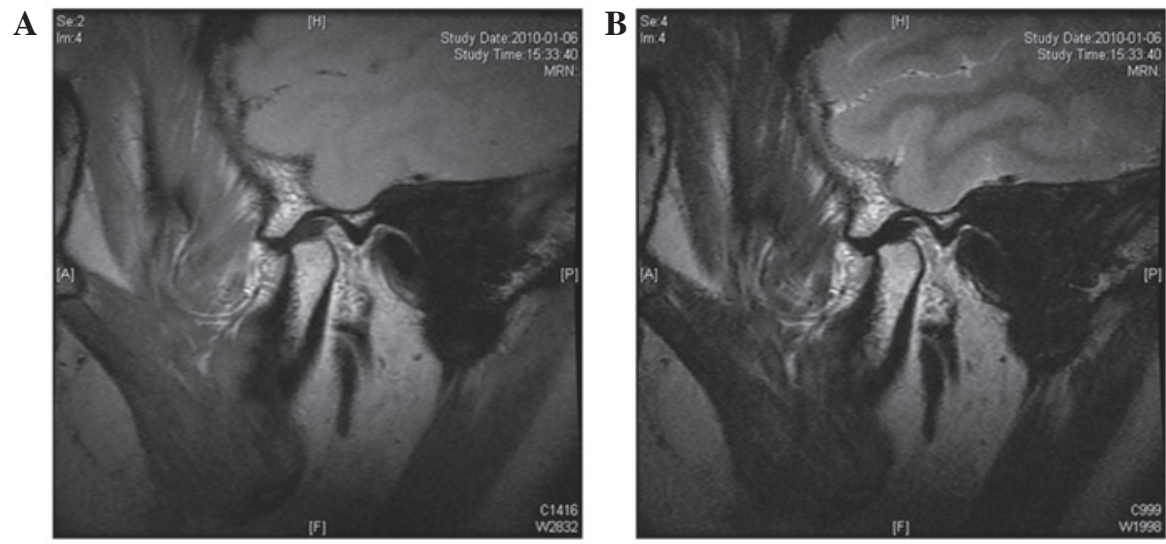

Figure 3. Preoperative magnetic resonance imaging (MRI) examination. Preoperative MRI reveals normal anatomic structures between the articular disk and the condyler in the (A) open and (B) closed jaw positions.

chronic periapical lesions of the right maxillary third molar residual root (Fig. 1A). Computed tomography (CT) scans (Fig. 2) revealed heterotopic bone formation in the right lateral pterygoid and medial pterygoid muscles (Fig. 2A and B). Normal anatomic structures between the articular disk and the condyle were observed on magnetic resonance imaging (MRI; Fig. 3A and B). Accounting for the medical history and clinicoradiological results, the patient was diagnosed with $\mathrm{MO}$ in the right lateral and medial pterygoid muscles.

Surgical excision was performed under general anesthesia and, following fiber optic assisted intubation, access to the mandibular was achieved via a preauricular incision, which extended to the temporal region and exposed the condylar process and sigmoid notch, as well as the coronoid process. To remove the calcification in the lateral pterygoid muscle and reduce the tension on the mandible caused by the temporalis, a right coronoidectomy was performed using a reciprocating saw. The majority of the calcified and fibrotic fibers of the upper head of the right lateral pterygoid muscle were removed. An additional intraoral approach to the medial aspect of the mandibular was adopted via a mucoperiosteal incision of the retromolar area to reveal and access the calcified medial pterygoid muscle. A pedicled buccal fat pad (BFP) flap was used to fill the dead space. A calcified mass was identified and subsequently excised. In addition, the masseter attachment was stripped from the ramus of the 


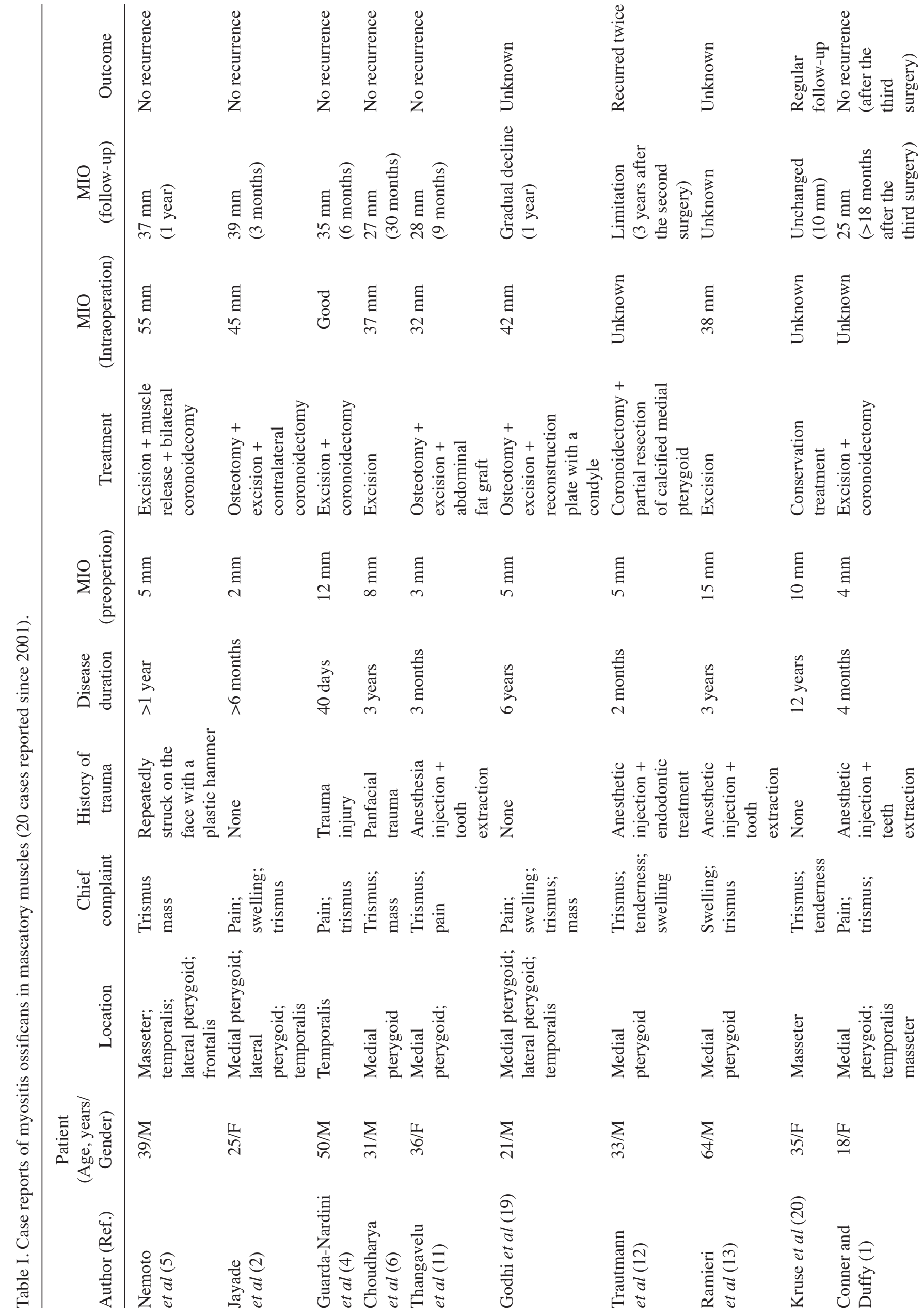




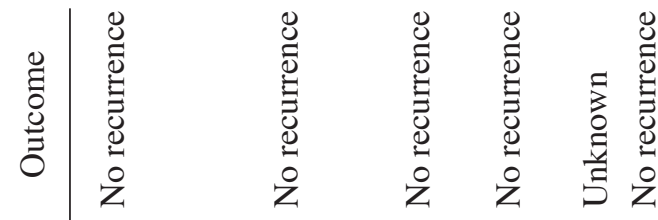

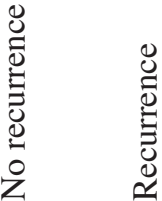

造

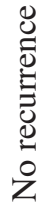

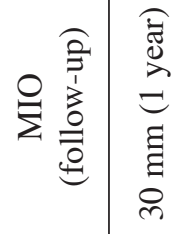

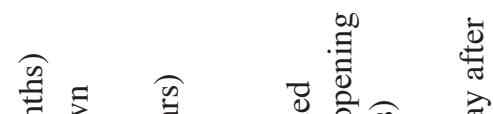

祘示

壱

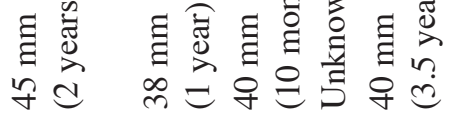

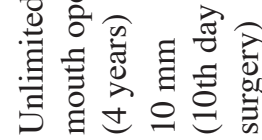

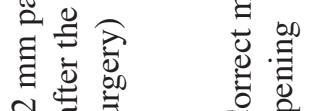

事苛

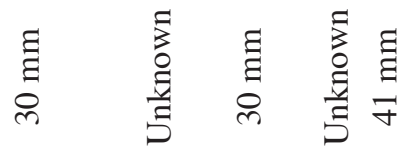

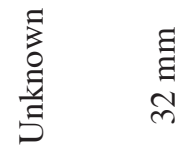

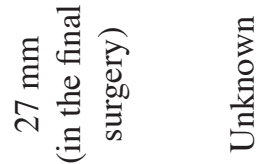

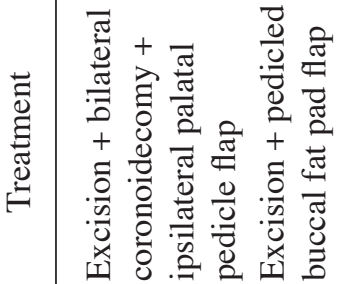
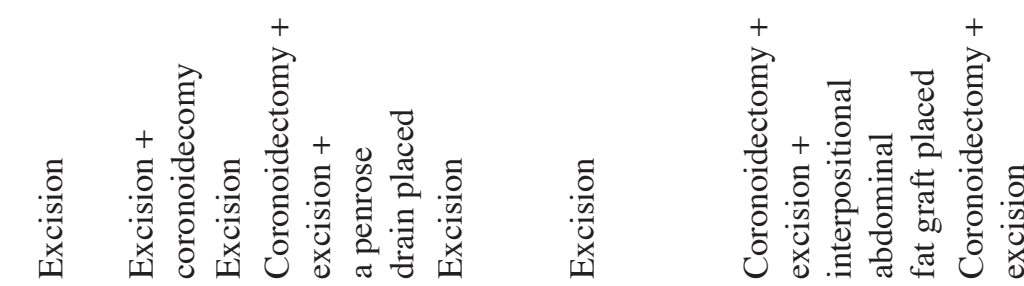

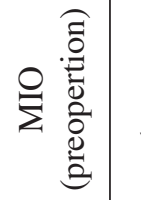

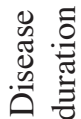

(2)

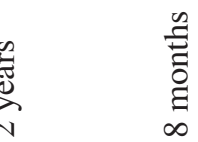

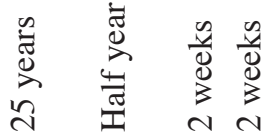

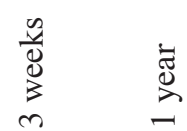

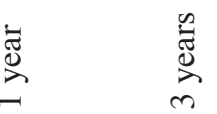

$\stackrel{0}{\Xi}$
$\stackrel{0}{0}$
$\underline{0}$

4

空节

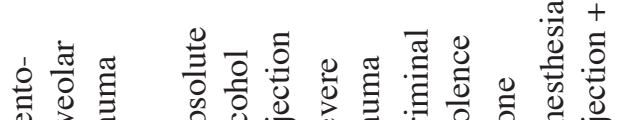

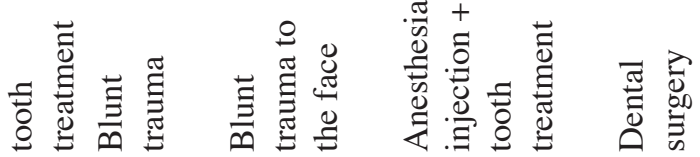

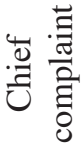
드

:

$\stackrel{0}{\Xi}$

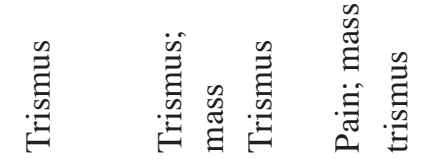

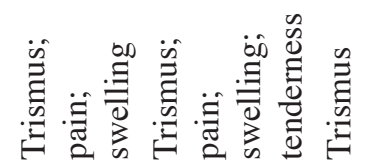

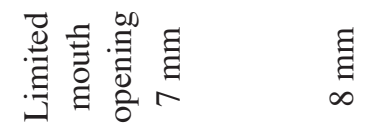

छี

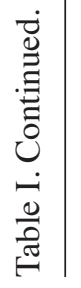

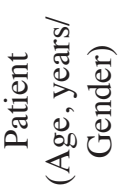

绨

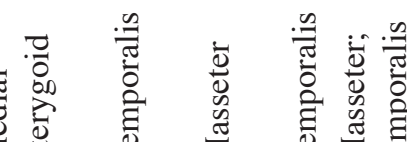

离

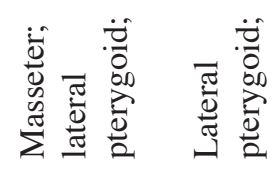

泀

ঙำ

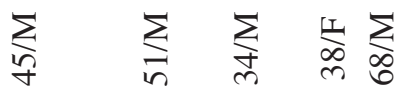

$\sum_{m} \sum_{j}^{J}$

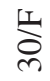

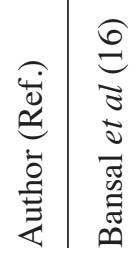

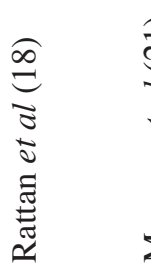

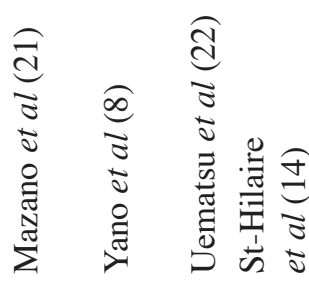

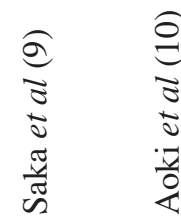

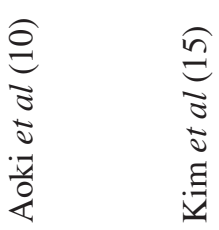

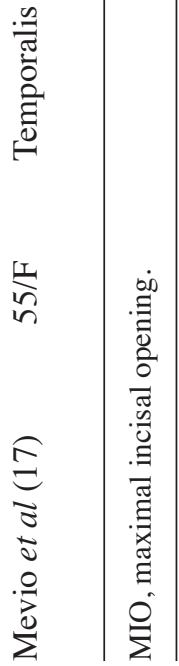


Table II. Clinical features of myositis ossificans in the masticatory muscles (20 cases reported from 2001) for 12 males and eight females (mean age, 36.75 years).

\begin{tabular}{lc}
\hline Parameter & Patients, $\mathrm{n}$ \\
\hline Location & 6 \\
Masseter & 6 \\
Lateral pterygoid & 11 \\
Medial pterygoid & 10 \\
Temporal & \\
Chief complaint & 20 \\
Trismus & 8 \\
Pain & 5 \\
Mass & 6 \\
Swelling & 3 \\
Tenderness & \\
Recurrence & 13 \\
No & 4 \\
Yes & 4 \\
Unknown & \\
\hline
\end{tabular}

Table III. Precipitating factors of myositis ossificans in the masticatory muscles (20 cases reported from 2001).

\begin{tabular}{llr}
\hline & \multicolumn{2}{c}{ Patients } \\
\cline { 2 - 3 } Precipitating factor & $\mathrm{n}$ & $\%$ \\
\hline Facial trauma & 8 & 40 \\
Local infiltration of anesthetics & 6 & 30 \\
Dental surgery & 1 & 5 \\
Local infiltration of absolute alcohol & 1 & 5 \\
Unknown & 4 & 20 \\
\hline
\end{tabular}

mandible to weaken the contractile force of the masseter muscle and mouth opening of $40 \mathrm{~mm}$ was achieved intraoperatively. The right maxillary third molar residual root was removed. The wound was closed in layers following the achievement of complete hemostasis. The healing period was uneventful and a postoperative panoramic radiograph and a CT scan were performed four days following surgery, which revealed that the ossification had been excised (Figs. 1B and 2C). Histopathology of the excised tissue specimens (Fig. 4) identified the novel formation of bone and osteoid within the muscle fibers. Physical therapy was initiated in the immediate postoperative period using suitable analgesics (200 mg celecoxib, twice a week, for one week) and was continued following discharge from the hospital. Maximum spontaneous mouth opening of $30 \mathrm{~mm}$ was achieved seven days following surgery.

The patient was followed up for a total of 36 months postoperatively. At present, the patient exhibits a stable interincisal opening of $25 \mathrm{~mm}$.

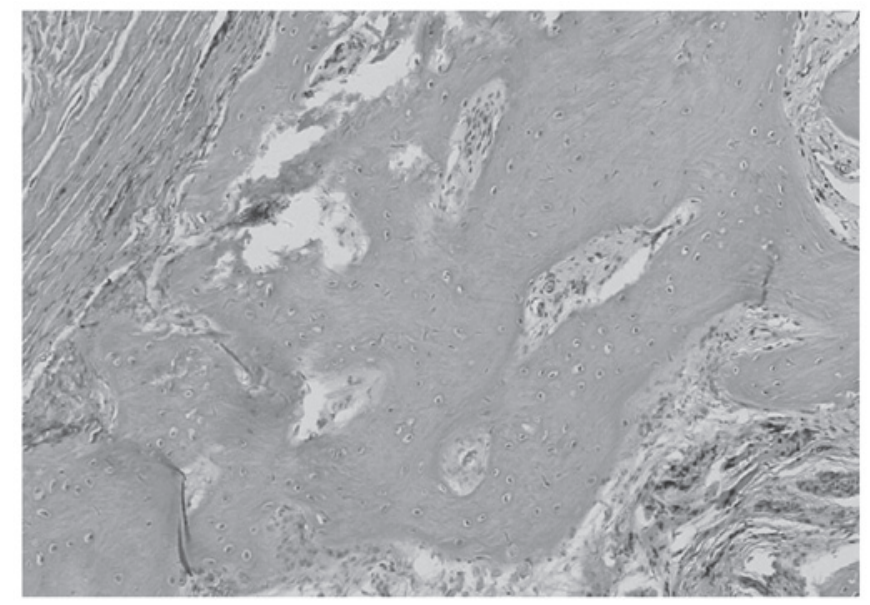

Figure 4. Microphotograph from the pathologic examination of the surgical specimen showing the characteristic features of connective tissue hyperplasia (osteoid and bone). Evident inflammatory cell invasion was observed surrounding the osseous tissue (stain, hematoxylin and eosin; magnification, x100).

\section{Discussion}

MO presenting in the masticatory muscles is rare; a review of the literature, which was conducted in the present study identified only 20 cases reported since 2001. The results of the literature review are presented in Tables I-III. The mean patient age was 36.75 years (range, 18-68 years). Nineteen of the 20 patients initially attended the hospital presenting with restricted mouth opening. Of the 20 patients, 16 were diagnosed with PTMO as a result of facial trauma (4-10), local infiltration of anesthetics $(1,11-15)$, dental surgery $(16,17)$ or absolute alcohol injection (18). However, the remaining four patients had no evident history of trauma, tooth extraction or infection $(2,19,20,22)$. Among the patients diagnosed with PTMO, males predominated (ratio of males to females, 11:5), which may be attributed to the fact that males are more likely to be subject to trauma in daily life (10). The region where PTMO most frequently occurred was the medial pterygoid muscles, which was often caused by a local anesthesia injection, followed by the application of external force directly to the temporalis and masseter muscles. The present review of the literature revealed that out of the 20 cases observed, the surgical management of one case (14) was performed at the early stage of PTMO in the temporalis without the observation of calcification, however, in the other cases, surgery was conducted when trismus occurred and calcification was identified via CT. In addition, of the 17 patients that were followed up, 10 patients were continued with the follow-up for more than one year and four patients exhibited recurrence subsequent to the first surgical treatment.

The exact mechanism for the pathogenesis of MO remains unclear, however, trauma is considered to be the inciting event. According to the literature, a signal, such as a bone morphogenetic protein (BMP) signal from the site of injury, may induce mesenchymal cells to differentiate into osteoblasts or chondroblasts, given the appropriate environment $(23,24)$. In the field of stomatology, odontogenic infection is a common condition when accompanied by trauma. In the present case, 
the smaller, superficial head of the medial pterygoid muscle, which originates from the maxillary tuberosity was proximal to the maxillary third molar. Therefore, apical periodontitis of the third maxillary molar may have spread toward the medial pterygoid muscles. Furthermore, infections in the medial pterygoid muscles may have spread toward the lateral pterygoid muscles through potential fascial spaces containing loose connective tissue. Long-term, low-grade inflammation may have stimulated the appropriate signaling agents, such as BMP, to induce heterotopic bone formation. Thus, it is hypothesized in the present report that infection and trauma exhibit an equally important role in the pathogenesis of MO in the masticatory muscles. Therefore, the present case was diagnosed as PIMO.

Ossification, the symptom of MO, may be observed by diagnostic imaging tests a minimum of 2-5 weeks subsequent to injury (25-27). After eliminating temporomandibular joint disease using MRI, CT and three-dimensional CT scans are considered to be particularly efficacious investigative tools in the oral and maxillofacial region. These imaging techniques aid with identifying the exact location and shape of the ossification, as well as establishing the association between the lesion and surrounding tissues, which is important for surgical treatment. Although a panoramic radiograph may not be effective for determining the exact extent of the lesion, due to the superimposition of the cranial bones, it may aid with the identification of odontogenic infection foci. Bone scans and ultrasound may also be used, however, are rarely applied for the craniofacial region (28).

Treatment of PTMO and PIMO usually includes surgical excision of the calcification and the surrounding muscles. Patients with MO of the temporalis or masseter area often undergo a coronoidectomy and the excision of the involved calcified muscles; whereas MO of the pterygoid muscle is more debilitating and, thus, the management of these types of patient is more complicated than that of the patients exhibiting MO of other masticatory muscles. According to the experiences of the present study, the following approaches should be considered: i) Transoral and extraoral approaches, which are often used to provide access to the medial aspect of the mandibular ramus to allow complete excision of the ossified muscle; ii) protection of the internal maxillary artery and inferior alveolar nerves (this is considered to be critical); and iii) using a BFP flap to fill the dead space for preventing hematoma formation and heterotopic bone reformation $(29,30)$. Two types of free fat, abdominal fat and the $\mathrm{BFP}$, have been reported that may serve as interpositional material. The BFP has been identified as a particularly effective autogenous tissue, which has been demonstrated in a multitude of surgical procedures in the maxillofacial region $(31,32)$. The BFP lies in close proximity to the site of surgery and may be used as a pedicled or random-pattern flap along with its own blood supply, so there are fewer instances of resorption when compared with an abdominal fat transfer.

In conclusion, a case of PIMO in the medial and lateral pterygoid muscles is presented and chronic low-grade infection was identified to be an important consideration in addition to other possible precipitating factors in the occurrence of MO. Panoramic radiography revealed the source of infection and CT scans effectively delineated the calcified mass. A positive outcome was achieved for the patient by the surgical excision of the calcification and ossified muscles, and via the use of a BFP flap to fill the dead space. This study indicates that symptomatic wisdom teeth must be removed as soon as possible, to prevent infection. In addition, it is important to considered infection as a factor which may lead to myositis ossificans.

\section{Acknowledgements}

The present study was supported by National Science Foundation of China (grant no's. 81100824 and 81070848) and the Foundation of Shanghai Municipal Education Commission (grant no's. 12YZ044 and 13XD1402300).

\section{References}

1. Conner GA and Duffy M: Myositis ossificans: a case report of multiple recurrences following third molar extractions and review of the literature. J Oral Maxillofac Surg 67: 920-926, 2009.

2. Jayade B, Adirajaiah S, Vadera H, et al: Myositis ossificans in medial, lateral pterygoid, and contralateral temporalis muscles: a rare case report. Oral Surg Oral Med Oral Pathol Oral Radiol 3: e1-e6, 2012.

3. Kaplan FS, Seemann P, Haupt J, et al: Investigations of activated ACVR1/ALK2, a bone morphogenetic protein type I receptor, that causes fibrodysplasia ossificans progressiva. Methods Enzymol 484: 357-373, 2010.

4. Guarda-Nardini L, Piccotti F, Ferronato G and Manfredini D: Myositis ossificans traumatica of the temporalis muscle: a case report and diagnostic considerations. Oral Maxillofac Surg 16: 221-225, 2012.

5. Nemoto H, Sumiya N, Ito Y, et al: Myositis ossificans traumatica of the masticatory muscles. J Craniofac Surg 23: e514-e516, 2012.

6. Choudharya AK, Sahoob NK and Chattopadhyaya PK: Myositis ossificans traumatica of the medial pterygoid muscle: A case report. J Oral Maxillofac Surg 24: 241-244, 2012.

7. Manzano D, Silván A, Saez J and Moreno JC: Myositis ossificans of the temporalis muscle. Case report. Med Oral Patol Oral Cir Bucal 12: E277-E280, 2007.

8. Yano H, Yamamoto H, Hirata R and Hirano A: Post-traumatic severe trismus caused by impairment of the masticatory muscle. J Craniofac Surg 16: 277-280, 2005.

9. Saka B, Stropahl G and Gundlach KK: Traumatic myositis ossificans (ossifying pseudotumor) of temporal muscle. Int J Oral Maxillofac Surg 31: 110-111, 2002.

10. Aoki T, Naito H, Ota Y and Shiiki K: Myositis ossificans traumatica of the masticatory muscles: review of the literature and report of a case. J Oral Maxillofac Surg 60: 1083-1088, 2002.

11. Thangavelu A, Vaidhyanathan A and Narendar R: Myositis ossificans traumatica of the medial pterygoid. Int J Oral Maxillofac Surg 40: 545-549, 2012.

12. Trautmann F, Moura Pd, Fernandes TL, et al: Myositis ossificans traumatica of the medial pterygoid muscle: a case report. J Oral Sci 52: 485-489, 2010.

13. Ramieri V, Bianca C, Arangio P and Cascone P: Myositis ossificans of the medial pterygoid muscle. J Craniofac Surg 21: 1202-1204, 2010.

14. St-Hilaire H, Weber WD, Ramer $M$ and Lumerman $H$ : Clinicopathologic conference: trismus following dental treatment. Oral Surg Oral Med Oral Pathol Oral Radiol Endod 98: 261-266, 2004.

15. Kim DD, Lazow SK, Har-El G and Berger JR: Myositis ossificans traumatica of masticatory musculature: A case report and literature review. J Oral Maxillofac Surg 60: 1072-1076, 2002.

16. Bansal V, Kumar S and Mowar A: Unusual causes of trismus: a report of two cases. J Maxillofac Oral Surg 8: 377-380, 2009.

17. Mevio E, Rizzi L and Bernasconi G: Myositis ossificans traumatica of the temporal muscle: a case report. Auris Nasus Larynx 28: 345-347, 2001.

18. Rattan V, Rai S and Vaiphei K: Use of buccal pad of fat to prevent heterotopic bone formation after excision of myositisossificans of medial pterygoid muscle. J Oral Maxillofac Surg 66: 1518-1522, 2008. 
19. Godhi SS, Singh A, Kukreja P and Singh V: Myositis ossificans circumscripta involving bilateral masticatory muscles. J Craniofac Surg 22: e11-e13, 2011.

20. Kruse AL, Dannemann C and Grätz KW: Bilateral myositis ossificans of the masseter muscle after chemoradiotherapy and critical illness neuropathy-report of a rare entity and review of literature. Head Neck Oncol 1: 30-35, 2009.

21. Manzano D, Silván A, Saez J and Moreno JC: Myositis ossificans of the temporalis muscle. Case report. Med Oral Patol Oral Cir Bucal 12: E277-E280, 2007.

22. Uematsu Y, Nishibayashi H, Fujita K, et al: Myositis ossificans of the temporal muscle as a primary scalp tumor. Case report. Neurol Med Chir (Tokyo) 45: 56-58, 2005.

23. Yu PB, Deng DY, Lai CS, et al: BMP type I receptor inhibition reduces heterotopic ossification. Nat Med 14: 1363-1369, 2008.

24. Katagiri T: BMP signaling and bone formation. Clin Calcium 22: 1677-1683, 2012.

25. Shirkhoda A, Armin AR, Bis KG, et al: MR imaging of myositis ossificans: variable patterns at different stages. J Magn Reson Imaging 5: 287-292, 1995.

26. Amendola MA, Glazer GM, Agha FP, et al: Myositis ossificans circumscripta: computed tomographic diagnosis. Radiology 149: 775-779, 1983.
27. McCarthy EF and Sundaram M: Heterotopic ossification: a review. Skeletal Radiol 34: 609-619, 2005.

28. Trautamann F, Moura Pd, Fernandes TL, Gondak RO, Castilho JC and Filho EM: Myositis ossificans traumatica of the medial pterygoid muscle: a case report. J Oral Sci 52: 485-489, 2010.

29. Chen MJ, Yang C, Qui YT, et al: Local resection of the mass to treat the osteochondroma of the mandibular condyle: indications and different methods with 38 -case series. Head Neck 36: 273-279, 2013.

30. Chen MJ, Yang C, Cai XY, et al: Synovial chondromatosis in the inferior compartment of the temporomandibular joint: different stages with different treatments. J Oral Maxillofac Surg 70: e32-e38, 2012.

31. Rattan V: A simple technique for use of buccal pad of fat in temporomandibular joint reconstruction. J Oral Maxillofac Surg 64: 1447-1451, 2006.

32. Stuzin JM, Wagstrom L, Kawamoto HK, et al: The anatomy and clinical applications of the buccal fat pad. Plast Reconstr Surg 85: 29-37, 1990. 